\title{
Dynamic Analysis of a Straight Bevel Gear Composite Structure
}

\author{
Al-Qrimli $\mathrm{HF}^{1 *}$, Almurib $\mathrm{HA}^{2}$, Kumar $\mathrm{N}^{2}$ and Mahdi $\mathrm{FA}^{3}$
}

${ }^{1}$ Department of Mechanical Engineering, Curtin University, CDT 250 98009, Miri, Sarawak, Malaysia

${ }^{2}$ Faculty of Electrical Engineering, University of Nottingham, 43500 Semenyih, Malaysia

${ }^{3}$ Department of Electrical Engineering, University of Baghdad, Jadriyah, Baghdad, Iraq

\begin{abstract}
In this paper, orthotropic materials are selected to be used as a straight bevel gear. These materials have the advantage of being light, are durable in high speeds, require the minimum need for oil, high strengths, and extra loading capacities. Due to these properties, it is highly preferable comparing to conventional materials. This work demonstrates a standard form of the straight bevel gear, to focus on the study of the behaviour of material. Based on the complex proportional assessment method, we selected the woven roving glass fibre as an optimum material to be used in the straight bevel gear model. From the results, it was determined that the composite gear is better in terms of specific energy absorption and dynamic behaviour compared to steel gears. From the results, the jute-epoxy shows a very low value of stiffness and it can be concluded that the natural fibre is not suitable to be used as a material for a straight bevel gear.
\end{abstract}

Keywords: Steel; Polymer-matrix composite; Gears; Finite element modelling

\section{Nomenclature}

MMC: Metal Matrix Composite

FRP: Fibre Reinforcement Plastic

COPRAS: complex proportional assessment method

SEA: Specific Energy Absorption

S: $\quad$ Stiffness

M: Mass of Gear

P: Load

SE: Stiffness Efficiency

C: $\quad$ Cost

EM: Easy Manufacturing

RS: Relative Significance

QU: Quantitative Utility

\section{Introduction}

Recent advances in material processing technology have propelled composite materials to the forefront of material technological development. Due to advantages such as high specific strength, high specific modulus, and special electrical properties, composite materials have attracted considerable attention within the engineering community, and are touted as potential substitutes for metals in automotive parts, aerospace structural parts, and transportation [1,2]. This is due to the fact that composites have good properties such as excellent corrosion resistance, high strength to weight ratio, high impact resistance and possesses design flexibility. These properties make parts manufactured from composite materials of high-quality, durable and cost-effective products [3]. Composite are flexible in terms of modifications, fatigue resistance, and the ability to absorb impact energy, making them very attractive to current industrial needs.

The literature on isotropic metallic gears is massive; however, the author has managed to locate some studies regarding gears made from composite materials. It was started by Ganesan and Vijayarangan, where they conducted an investigation comparing the performance of a spur gear fabricated using metal matrix composite (MMC) materials, to that made of conventional steel materials, and analyzed its static behaviour in three dimensions using finite element analysis [4]. They concluded that the behaviour and performance of both MMC material gears and the mild steel gear are quite similar, with the safety factor for the metal matrix composite showing the lowest values relative to other materials. After that Senthilvelan and Gnanamoorthy reported that gear tooth with less fillet radius fails via crack initiation at its root, while the large fillet radius fails by micro-cracking at the midpoint of the tooth [5]. In response to this discovery, they used injection-molded gear, made from Nylon 6/6. Moreover, Cedergren, demonstrated a method using a gear wheel to determine the porosity distribution within a complex powder compacted 3D structures with a dynamic 3D dilatant finite strain finite element program [6]. The analysis showed that the porosity distribution in the gears is dependent on the number of the gear's teeth, thickness of the inner ring, the pressure angle, and is an excessive influence to the values of the porosity, which will induce small changes in its geometrical parameters. They stated that the minimum porosity distribution in the metal matrix composite gear is $3 \%$, and this is achieved by maximum compaction during molding. However, this ratio is inadequate to prevent the gear's tooth from the initiation and propagation of cracks. Later on Ramesh and Ganesan used metal matrix composites (MMC) in a railway wheel, and compared them with steel and fibre reinforcement plastic (FRP) wheels from a static point of view [7]. They concluded that the deflection in MMC is much lower than that of FRP. Junichi et al. studied the tribology of a metal gear

*Corresponding author: Al-Qrimli HF, Department of Mechanical Engineering, Curtin University, CDT 250 98009, Miri, Sarawak, Malaysia, Tel: +6085-443939; Fax: +6085-443838; E-mail: haidar.fa@curtin.edu.my, halqrimli@yahoo.com

Received November 26, 2014; Accepted January 23, 2015; Published January 31,2015

Citation: Al-Qrimli HF, Almurib HA, Kumar N, Mahdi FA (2015) Dynamic Analysis of a Straight Bevel Gear Composite Structure. J Material Sci Eng 4: 152. doi:10.4172/2169-0022.1000152

Copyright: (C) 2015 Al-Qrimli HF, et al. This is an open-access article distributed under the terms of the Creative Commons Attribution License, which permits unrestricted use, distribution, and reproduction in any medium, provided the original author and source are credited. 
and a hybrid gear in order to reduce noise with greaseless metal gear and plastic gear, with smaller rates of tooth failure [8]. They discovered that the noise is suddenly amplified when a single polymer sheet was spontaneously removed from the gear's surface, probably due to its low adhesive strength against shear. Likewise Masaya et al. improved the performance of a plastic gear by using five types of carbon fibres blended with poly-ether-ether-ketone (PEEK) [9-11]. They evaluated the load capabilities and the wear properties of the reinforcement material used, and the results showed that the carbon fibre reinforced composite gear have superb affinity with PEEK. Hoskins and his group tested five types of materials; Polyoxymethylene, Unreinforced polyetheretherketone, Carbon fiber reinforced, Polyamide, and Glass fibre reinforced in order to provide the opportunity to minimize transmission errors of design development in gears [12]. Senthilvelan and Gnanamoorthy experimentally studied the effect of various rotational speeds and stress on the performance of unreinforced Nylon 6 spur gears and glass fibre reinforced Nylon 6 spur gears [13]. The result showed that speed has no influence on the gear's life on both under low stress levels. Simon presents an optimal tooth modification for a spiral bevel gear that improves load distribution and decreases the maximum tooth contact pressure, while Yilmaz and Cenk investigated the fatigue behaviour at the roots of gear teeth and hardness distribution along the radial direction of the tooth $[14,15]$. They compared the results with a number of experiments for model validation purposes. Mendi et al. manufacture a gear made from polypropylene, reinforced with three different metallic springs, and they concluded that the increase in the diameter of the reinforcement spring will increase the service life of the gear 30 times more than gears without metallic springs [16]. Aslantas and Tas carried out a series of experimental and numerical analysis on a spur gear made from austempered ductile iron to predict the pitting occur of the gear teeth [17]. They conclude that the pitting failure time can be predicted without testing gear. Meanwhile, Hayrettin increased the width of the gear's teeth and studied the thermal damage on a single gear tooth surface [18]. He managed to experimentally delay the thermal damage of the tooth's surface on maximum Hertzian surface stress. Letzlter et al. manufactured a gear made from Polyamide 6.6 material, and demonstrated an efficient method to predict the mechanical behaviour of the gear, while calculating the load sharing with local meshing stiffness over the entire surface of the gear tooth [19]. Toshiki and others looked on the cotton fibre reinforced plastics to be used as an industrial gear material. They estimate the gear root stresses under running condition caused by bending consequences [20]. They confirmed that a plastic gear made from cotton fibre is batter in terms of noise quality. We used the complex proportional assessment (COPRAS) method to determine the optimum material to be used for the gear. This method is one of the most common methods in determining the best designs. It was created by to solve the selection problems of engineering using the stepwise ranking and alternative procedure in terms of their significance [21-23]. Straight bevel gears made of composite materials have been investigated, and the materials selected are woven fibreglass, carbon-fibres, and natural-fibres (Jute). The reinforcement mixture of the composite will be epoxy/resin, while the selection of the constituents of the composite is based on extensive literature review on the subject. In this paper we started with the methodology, results and discussion and finally the conclusion. The first step of the methodology is the numerical procedure by using finite element method. After that we used COPRASS method to select which material is the best to be used as a straight bevel gear. The procedure and the equations of this method will be discussed. After finding the best material we make an attempt to manufacture the straight bevel gear experimentally to ensure that the product is successfully working as expected. The manufacturing process and the results will be discussed also. Not to mention, the authors trace scarce literatures on a straight bevel gear. Most of the papers found are on spur gear and using one type of material while this study will discuss different type of materials for a straight bevel gear.

\section{Specific Energy Absorption (SEA)}

The imperative factor in parts design is the specific energy absorption (SEA). This allows determining the requirements for the weight reduction of multiple structures such as gears, robotic arms and other mechanical components. SEA is defined as the total energy absorbed (stiffness) per unit mass of the specimen, with an SI unit of $\mathrm{kJ} /$ $\mathrm{kg}$. It is represented by equation 1 .

$$
S E A=S / M
$$

where $S$ is the total energy absorption and $M$ is the mass of the gear.

The total energy absorption (S) is the area under the load strain curve, and it can be numerically calculated by integrating the load displacement curve. In this study the post-stage of the material development have been considered due to its importance compared to the pre-stage.

$$
S=\int_{s_{i}}^{s_{f}} P d s
$$

where $P$ is the load, $S_{i}$ is the initial displacement and $S_{f}$ is the final displacement.

\section{Methodology and Procedures}

There are three main stages in this investigation. The first stage is dubbed the numerical stage; the second stage involves the choosing of the optimum material, and the final stage involves actual experimentation. Figure 1 summarizes the whole procedure that was used in this work to realize the orthotropic straight bevel gear.

\section{Numerical procedure}

Gear simulation presents itself as one of the most strenuous problem in mechanical design due to the fact that it includes all sources of nonlinearity that has to be incorporated and taken into account during multiple stages of its development. A gear's structural is made up of a complex geometrical configuration and different materials, and experiences high impact load during operation, which results in high stresses. These high stresses, if they exceed the critical limit of material's

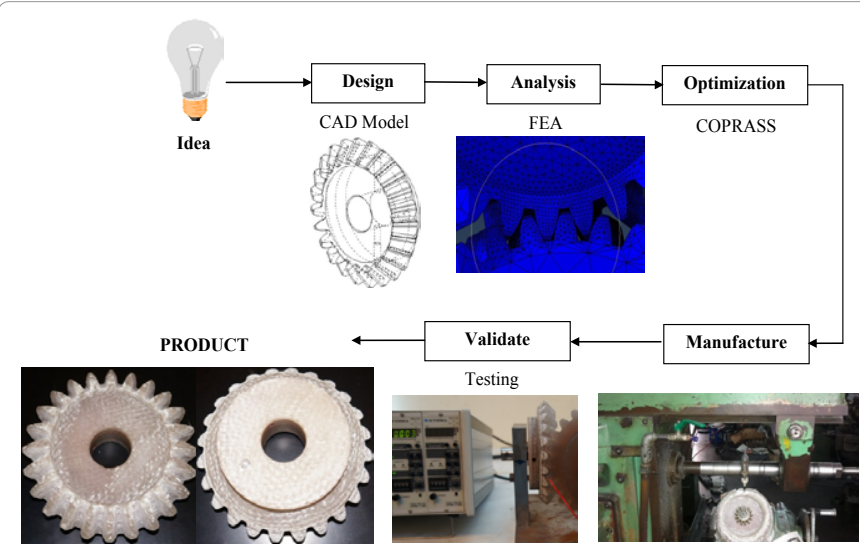

Figure 1: Concept and reality flowchart for straight bevel gear design. 
yield, will force the structural components to undergo large progressive elastic-plastic deformation. This whole process occurs within a very short time span. As a result in this stage a standard element is used with 3D stress for dynamic and explicit test, with triangular element types. The global size of the mesh is 1.5 in a three connected teeth on the gear and pinion, but on the other surfaces of the gear, a value of 15 is used for the mesh of the global size instead, while in the two shafts, a global size of 20 is considered due to the fact that it is assumed to be a rigid body and therefore, unimportant. The maximum deviation factor is 0.1 , which is a default value for the entire straight bevel gear domain and all the defined parts. The boundary conditions of any finite element problem need to be determined, and in this work, the boundary conditions that are used are similar to the experimental phase. A torque is applied on one side of the gear, while all the points along the second gear are fixed in every direction, with zero degrees of freedom. For simplicity, the boundaries are shown in Figure 2. The pinion is fixed in all six directions $(\mathrm{DoF}=0)$, while the load condition looks to be an external torque, applied on the gear. The magnitude of the applied torque used in the present work is (17640 N.m), which results in the tangential force of the gear's tooth surface of $(245 \mathrm{~N})$. All the standard parameter used to construct the straight bevel gear is shown in Table 1. The apparent absence of the gear's parameter effect allows us to focus on the study of the behaviour of material. In the model and within the scope of our work, both the teeth's surface interacts with single surfaceto surface (ASTS) contact between the gear's materials. A tie constraint was used to bond the rigid shafts to the gears using nodes, as shown in Figure 2.

\section{Complex Proportional Assessment Method Steps (COPRAS)}

The preliminary development of manufactured goods depends on the theoretical design of the model, derived from the customer's requirements. To optimize the product's cost, the engineering calculations must be as precise as possible, with little to no margin of error(s). Material selection and design are important factors that

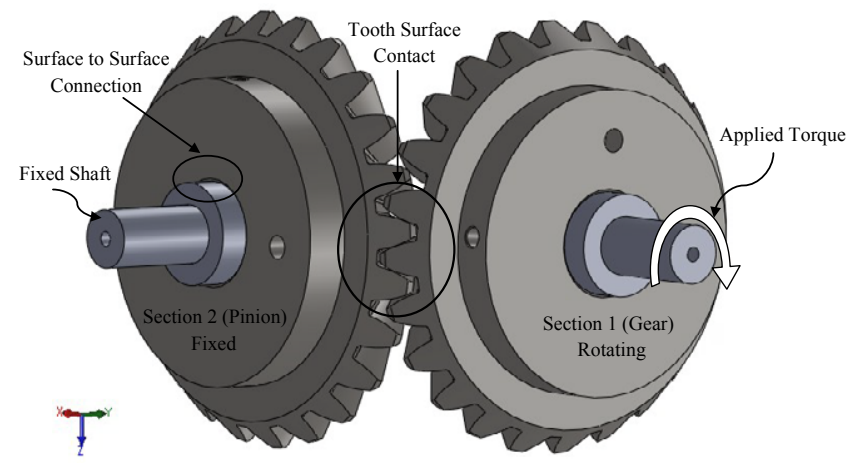

Figure 2: Boundary conditions of the straight bevel gear.

\begin{tabular}{|c|c|c|c|}
\hline NO. & Design Parameter & Value & Options \\
\hline 1. & Pressure angle & $20^{\circ}$ & \\
\hline 2. & Module & 6 & Material model \\
\hline 3. & Face width & $28.5 \mathrm{~m}$ & Glasses/Epoxy \\
\hline 4. & Addendum & $1 \mathrm{~m}$ & Carbon/Epoxy \\
\hline 5. & Dedendum & $1.25 \mathrm{~m}$ & Jute/Epoxy \\
\hline 6. & Shaft angle & $90^{\circ}$ & Chopped/Epoxy \\
\hline 7. & Root fillet radius & $0.3 \mathrm{~m}$ & Steel \\
\hline 8. & Number of teeth & 24 & \\
\hline
\end{tabular}

Table 1: Standard gear parameters.

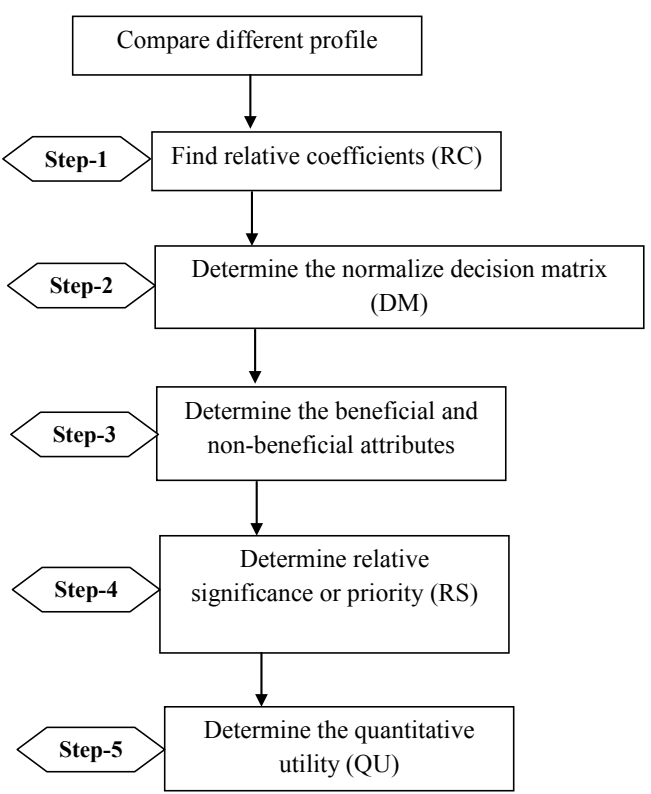

Figure 3: Steps of Complex Proportional Assessment Method (COPRAS)

\begin{tabular}{|c|c|c|c|c|}
\hline Material/Criteria & Steel & Glass/Epoxy & Carbon/Epoxy & Jute/Epoxy \\
\hline S & 14.96 & 12.38 & 14.41 & 9.564 \\
\hline SEA & 4.98667 & 20.6408 & 26.2056 & 10.6272 \\
\hline SE & 0.3622 & 0.3956 & 0.3675 & 0.3961 \\
\hline FE & 0.605343 & 0.694564 & 0.684821 & 0.663324 \\
\hline C & 380 & 610 & 1080 & 470 \\
\hline EM & 1 & 2 & 2 & 3 \\
\hline
\end{tabular}

Table 2: Criteria with profiles used for selecting the best design.

must also be taken into account. The complex proportional assessment method (COPRAS) is a suitable method that solves the problems of material selection for a straight bevel gear. Figure 3 explains the main steps of this method.

Step 1: Develop the Initial Matrix (X) and Find the Relative Coefficient (RC)

This step contains a matrix with values from 1 to 3 ; the decision is in accordance with the significance of the factors; its criteria shown in Table 2. The matrix obtains the positive decision.

$$
X=\left[x_{i j}\right]_{m \times n}
$$

where $x_{i j}$ is the performance value of the $i$-th alternative on $j$-th criterion, $m$ is the number of alternatives compared and $n$ is the number of criteria. $x_{i j}$ represents the positives for each criterion. The symbol of the relative coefficient is RC, and it is formulated as

$$
R C=\left[r_{i j}\right]_{m \times n}=\frac{x_{i j}}{\sum_{i=1}^{m} x_{i j}}
$$

where $\sum_{i=1}^{m} x_{i j}$ is the summation for a number of positives decisions. The importance of the relative coefficient is that it reduces the values of the criteria to simplify comparisons.

Step 2: Determine the Weighted Normalized Decision Matrix DM

$$
D M=\left[y_{i j}\right]_{m \times n}=r_{i j} \times w_{j}
$$


$w_{j}$ is the weight for each criteria; with the summation of the normalized weight for each criteria always equal to the weight of the same mentioned criteria.

\section{Step 3: Beneficial and non-Beneficial Attributes}

The values of the normalized decision matrix contain beneficial and non-beneficial attributes. The next step involves division according to their importance. The cost and manufacturing toughness with lower values are considered non-beneficial attributes, whereas the rest of the criteria are considered beneficial attributes. These two factors are formulated into two equations:

$$
\begin{aligned}
& S_{+1}=\sum_{j=1}^{n} y_{+i j} \\
& S_{-1}=\sum_{j=1}^{n} y_{-i j}
\end{aligned}
$$

where $y_{+i j}$ and $y_{-i j}$ are the beneficial and non-beneficial attributes respectively, with the best alternative depending on the greater value that is considered beneficial, and the lower value with non-beneficial attribute. The summation of the minuses also represents the attributes to help find the priorities.

$$
\begin{aligned}
& S_{-}=\sum_{i=1}^{m} S_{-i} \\
& S_{+}=\sum_{i=1}^{m} S_{+i}
\end{aligned}
$$

The sum of $S_{-}$and $S_{+}$are always equal to one, and the separate summation is equal to the sums of the weight of the beneficial and nonbeneficial attributes and this to ensure that the formals used is exact.

\section{Step 4: Relative Significance or Priority (RS)}

The priorities of the alternative have been calculated, and it is surmised that the higher the value of $\mathrm{RS}_{i}$, the greater the priority of an alternative will be. The alternative with the maximum relative significance $\mathrm{RS}_{\text {max }}$ is considered the best selection for the application design. The relative significance has been formulated below:

$$
R S_{i}=S_{+i}+\frac{S_{-\min } \sum_{i=1}^{m} S_{-i}}{S_{-i} \sum_{i=1}^{m}\left(S_{-\min } / S_{-i}\right)}
$$

\section{Step 5: Determine the Quantitative Utility (QU)}

The value of the quantitative utility is directly related to relative significance; with the values of the quantitative utility completing the ranking of the alternatives, denoted by the equation below:

$$
Q U_{i}=\frac{R S_{i}}{R S_{\max }}
$$

The maximum value of relative significance is denoted as $R S_{\max .}$ The quantitative utility is directly proportional to the relative significance, and the utility value with a 100 is considered as the best design in this method.

\section{Experimental gear process}

As mentioned previously, the composite material that will be used is woven fibre and epoxy. The ratio of the mixture of this composite is $4: 1$. The first stage of manufacturing involves the preparation of the materials, along with the equipment, in order to fabricate a circular tube. The fibre is cut into the desired diameter in order to allow it to comfortably fit into the mandrel. After that, a tube was used to arrange the fibre layers until it reaches the desired thickness. While arranging the fibre layers, each layer are carefully brushed. Brushing should be done in equal distribution in order to produce balanced tubes and symmetrical dimensions for all parts of the tubes. Then, weights are added to the top of the tube to ensure strong adhesion between the layers, and also to ensure that no bubbles are formed in the structure. Upon completion, the specimens should be left for at least eight hours to make sure that the epoxy resin is truly dried. In this research, the tubes are exposed to air for ten hours to ensure the completion of epoxy curing. Moreover, the tubes should be able to vertically stand in order to prevent any of tubes' faces from touching any surfaces. Figure 4 shows the gear manufacturing stages. At this point of the process, the tubes are ready for cutting, and at this stage, the tubes will be turning first, which turns it to a gear blank. The next stage will be the teeth generation by using a gear-cutting machine shown in the Figure 4. In the experiment strain gauge test, a steel base was developed to attach the two composite bevel gears and allow a small amount of backlash to attach the strain gauge on the gear tooth. The base is made from steel, with a square cross-section of $20 \mathrm{~mm}$ thickening, with the two shafts and ball bearing allowing the gears to rotate smoothly. The base has a stopper to fix one of the gears in order to perform the test. Figure 5 shows all the details of the CAD drawing, and the actual prototype.

\section{Results and Discussion}

\section{Force time history}

The crash duration is paramount to the gear's tooth surface capacity to withstand loading, as it characterizes the gear's tooth damage. The force-time curve can determined the total loading time of the tooth. Figure 6 shows a compression of the force and the time curves in the models of steel, glass, carbon and jute fibre, showing a linear behaviour in the elastic zone, until it reaches the peak force to fall down due to the reaction of the gear tooth surface. This occurs in all the models. From the Figure, it is obvious that the maximum force (peak) is equal to the initial failure force in the four models. After that, the curves observed a sharp drop, and start fluctuating until it reaches $0.005 \mathrm{sec}$, and the curve

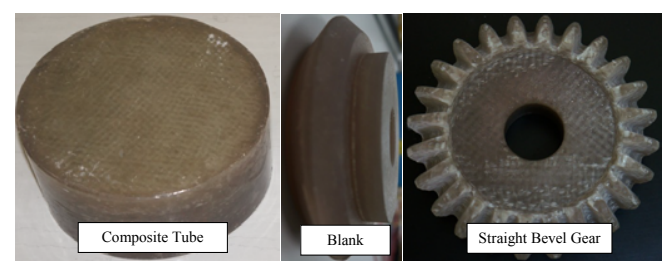

Figure 4: Gear specimens manufacturing process.

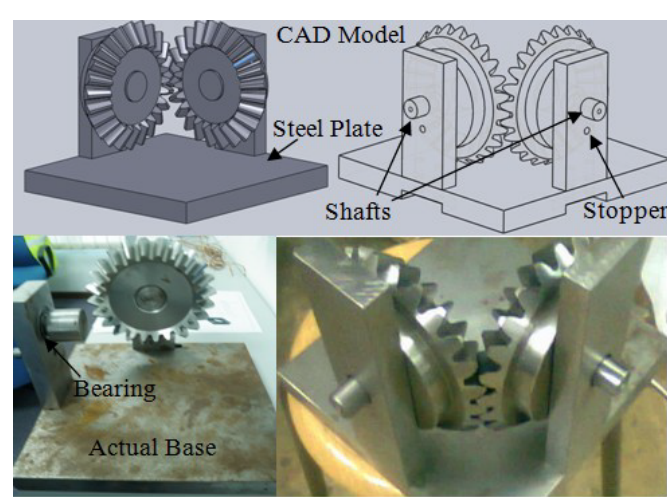

Figure 5: Straight bevel gear base 


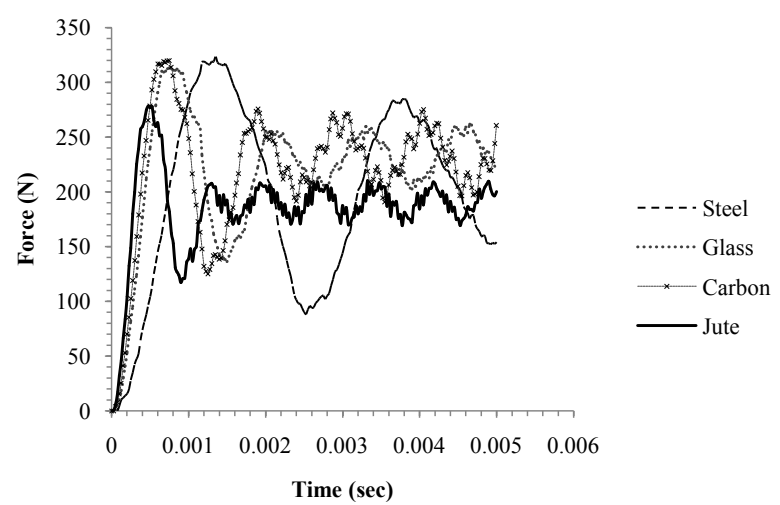

Figure 6: Total contact forces of straight bevel gear made from steel.

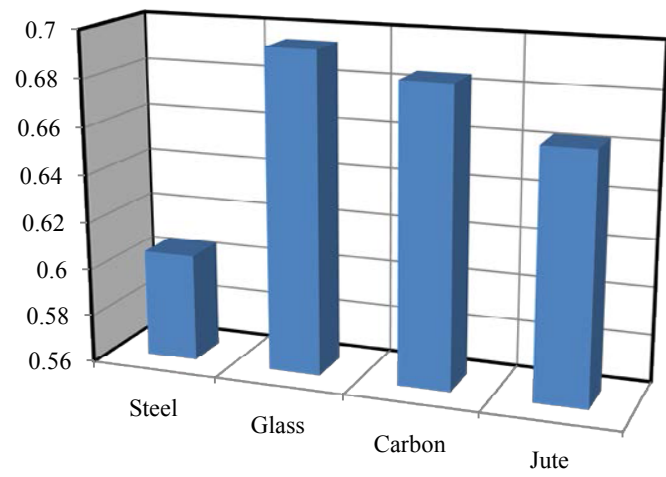

Figure 7: Force efficiency of gear tooth with diffrint type of materail (steel glass, carbon, jute).

\begin{tabular}{|l|c|c|c|c|}
\hline Material Parameter & Steel & $\begin{array}{c}\text { Glass Fibre/ } \\
\text { Epoxy }\end{array}$ & $\begin{array}{c}\text { Carbon } \\
\text { Fibre/Epoxy }\end{array}$ & $\begin{array}{c}\text { Jute Fibre/ } \\
\text { Epoxy }\end{array}$ \\
\hline Stiffness $(\mathrm{kJ})$ & 14.96 & 12.38 & 14.41 & 9.564 \\
\hline Max. Force $\left(\mathrm{P}_{\max }\right)(\mathrm{N})$ & 323.28 & 313.45 & 319.91 & 278.32 \\
\hline $\begin{array}{l}\text { Specific Energy } \\
\text { Absorption (SEA) }(\mathrm{kJ} / \mathrm{kg})\end{array}$ & 4.98667 & 20.6408 & 26.2056 & 10.6272 \\
\hline Force Efficiency (FE) & 0.605343 & 0.694564 & 0.684821 & 0.663324 \\
\hline Average Force $\left(\mathrm{P}_{\mathrm{av}}\right)(\mathrm{N})$ & 195.698 & 217.711 & 219.083 & 184.618 \\
\hline
\end{tabular}

Table 3: Straight bevel gear parameters for different type of materials.

stops, because it is at the end of the time step. The fluctuation behaviour in the three composite models shows a similar trend, but in steel the fluctuation is different due to its dissimilar mechanical properties. This fluctuation of the curves is due to the matrix deformation and the structure recovery of the materials. The peak force values occurring by the straight bevel gear made from steel shows the highest value, which is $323.285 \mathrm{~N}$ at time step of $0.00135 \mathrm{sec}$, while the carbon fibre comes next at $319.912 \mathrm{~N}$ in $0.00075 \mathrm{sec}$. The glass fibre straight bevel gear shows an intermediate result in total, and the value of the force is close to the carbon gear, at $313.45 \mathrm{~N}$ in the same time step $0.00075 \mathrm{sec}$. The jute fibre shows the lowest values, as expected $(278.323 \mathrm{~N}$ at time of $0.00048 \mathrm{sec}$ ).

\section{Force Efficiency (FE)}

FE serves to evaluate the process's structural performance, and is defined by average load divided by the produced maximum load. Figure 7 and Table 3 shows all the FE for the different type of materials used in the straight bevel gear, with the performance of glass fibre gear being more efficient than the other models, which proves that it is the best for an energy absorbing system design that deals with complex structures and is applicable anywhere. But, as shown in Figure 7, the steel gear shows the lowest value of the force efficiency and all the orthotropic materials absorb higher values, which mean that using orthotropic materials improves the performance of the gear. In the energy absorbing system design, it is better to use the glass fibre, as it is more efficient than other orthotropic materials as it can be seen in Figure 7.

\section{Stiffness time history}

By using the finite element method we applied the explicit dynamic analysis (Structural dynamic analysis) to take into account how the gear's tooth surface responds to the applied toque. This enables us to determine the model's analysis in the pre-processing stage. A stress (es) that is observed on the gear's model is shown in Figure 8. In the Figure, before the master surface (gear) touches the slave's surface (pinion), the tooth is blue in colour, signifying a state of zero stress. After that, it's shown that the maximum stress during the entire test occurs in the middle of the tooth surface. The green colour is to signify the maximum stress. Basically, the weak areas in the models are in the middle of the gear tooth surface, as shown in the Figure 8. It can be noticed that the jute fibre/epoxy have higher stress comparing to the other materials, while the steel shows low effect.

The areas under the curves in Figure 9 are divided into two regions; the first region is classified as the pre-crashing region. The value is determined by calculating the area under the triangle; which is $1 / 2$, multiplied by the initial load and the initial displacement, with an SI unit of kN.m (kJ). The stiffness can therefore be determined by summing up two region's absorbed energy (pre and post stages). From Table 3, and as shown in the Figure 9, the highest stiffness is produced by steel, followed by carbon fibre, glass fibre and finally, jute fibre. From the results, it is clear that the type of material affects the stiffness of the tooth gear, the most effective being steel. However, Table 3 shows a very small difference.

It is surmised from Table 3 that gears made from carbon fibres has the highest specific energy absorption, even though the energy absorbed $(S)$ by the steel gear is higher than that of the carbon gear,

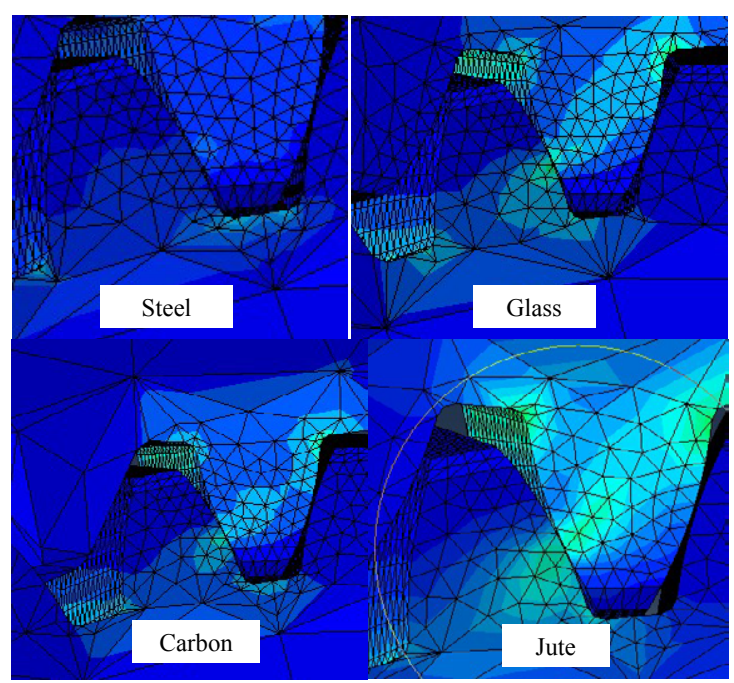

Figure 8: Stress distribution of straight bevel gear at time $(\mathrm{t}=0.001)$. 


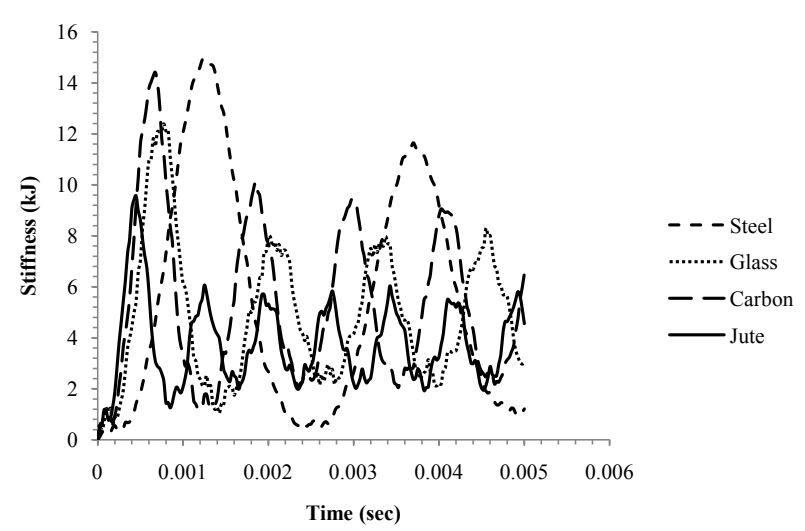

Figure 9: Time history of gear tooth stiffniss.

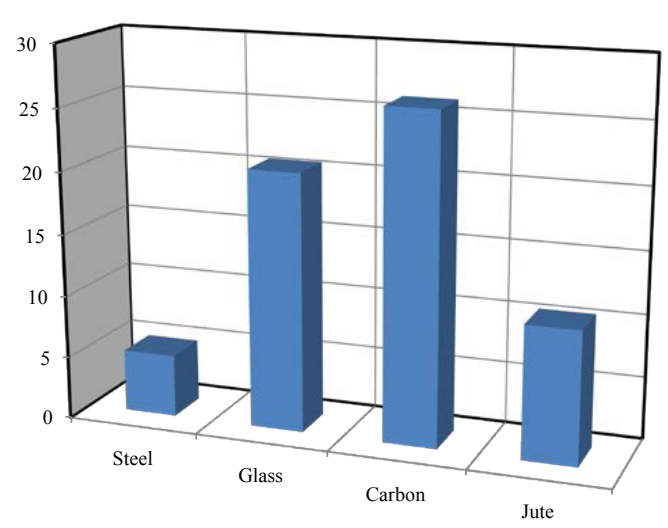

Figure 10: Specific energy absorption of steel, glass, carbon, jute straight bevel gear.

which incidentally, weighs less than steel. By applying the specific energy equation (equation 1 ) to determine $S E A$, the result of the carbon gear will be highest, followed by the glass fibre, with jute fibre falling behind fibreglass. Steel had the lowest values of SEA, suggesting that weight affects $S E A$, as the reduction of the gear's weight will increase its reliability. Figure 10 shows the specific energy absorption of all the straight bevel gears. Carbon fibres/epoxy seems to have the strongest specific energy absorption, with steel gears having the lowest.

\section{Design parameter selection}

The $S E A$ is to be the first and most important criteria for design selection. Force Efficiency ( $F E$ ) is obtained by dividing the average force gathered from the finite element method with the maximum force; a value closest to 1 considered the best FE. This parameter is very important due to the fact that it shows the behaviour and the state the materials are in, and this parameter is considered beneficial in the design selection criteria. The cost of the raw materials and the process of the manufacturing of the gear depend mostly on the suppliers of the gear's design. The manufacturing and the machining of the steel straight bevel gear (isotropic) are simpler, and consist of many methods compared to the composite material. For composite materials, it is more expensive and difficult to machine, and between the composite constituents, carbon fibre is very expensive, while glass and jute is very cheap. The exact values for the selected materials and the different criteria that have been chosen for the optimum design are shown in Table 2. Based on Equation 3, the positive decision ( $x$ ) was calculated, and Equation 4 was used to find the relative coefficient. To find the values of beneficial and non-beneficial parameters, Equation 6 and 7 are utilised. Then, the results of the summation were determined by applying Equation 8 and 9. The six mentioned criteria include both beneficial and non-beneficial attributes, according to the normalized decision matrix values. These beneficial and non-beneficial attributes should be separated according to the importance of the affected criteria, as shown in Table 4 . The best profile depends on the greater value of the beneficial attribute, and the lower value of the non-beneficial attribute. The relative significance $(R S)$ values depend on Equation 10, as mentioned previously. The best choice for the profile is the one with the greater number of relative significance, which is ranked accordingly in Table 5 . The final step in the process of the COPRAS method is to calculate the quantitative utility values by applying Equation 11, with the values shown in Table 5 . The values of the quantitative utility are directly related to the relative significance $(R S)$. Both the relative significance and the quantitative utility are responsible for the choice of the optimum straight bevel gear material.

The Complex proportional assessment method (COPRAS) has been performed, and the ranking values for six alternatives have been denoted. The $R S$ and $Q U$ proved that the carbon/epoxy and glass/epoxy is the optimum material for straight bevel gear applications. Based on these results, we decided to manufacture a straight bevel gear made from glass-fibres.

\section{Composite straight bevel gear}

The composite structure of these gears will contain two distinct materials, namely the fibre reinforcement material and its matrix, in

\begin{tabular}{|l|c|c|c|}
\hline Material & $\begin{array}{c}\text { Beneficial } \\
S_{+i}\end{array}$ & $\begin{array}{c}\text { Non-Beneficial } \\
S_{-i}\end{array}$ & $S_{-i} / \min S_{-i}$ \\
\hline Steel & 0.164912949 & 0.02767 & 1 \\
\hline Glass/Epoxy & 0.221751478 & 0.04035 & 0.68568 \\
\hline Carbon/Epoxy & 0.248192544 & 0.08394 & 0.3296 \\
\hline Jute/Epoxy & 0.16514303 & 0.04804 & 0.57595 \\
\hline Attributes & $\sum S_{+i}=0.8$ & $\sum S_{-i}=0.2$ & $\sum=2.59123$ \\
\hline
\end{tabular}

Table 4: Beneficial and non-beneficial values.

\begin{tabular}{|l|c|c|c|}
\hline Gear Material & $\boldsymbol{R S}$ & $\boldsymbol{Q U}$ & Ranking \\
\hline Steel & 0.24209631 & 88.13926579 & 3 \\
\hline Glass/Epoxy & 0.274674752 & 100 & 1 \\
\hline Carbon/Epoxy & 0.273632339 & 99.62049185 & 2 \\
\hline Jute/Epoxy & 0.209596598 & 76.30719471 & 4 \\
\hline
\end{tabular}

Table 5: Relative Significance $(R S)$ and Quantitative Utility $(Q U)$ values with ranking.

\begin{tabular}{|c|c|c|c|c|}
\hline Properties & \multicolumn{4}{|c|}{ Strain } \\
\hline Gear Material & Steel & \multicolumn{3}{|c|}{ Glass Fiber E-200 } \\
\hline Gear Weight (Kg) & 3 & & 0.60 \\
\hline Applied Force (N) & Isentropic & $\mathbf{0}^{\circ}$ & $\mathbf{9 0}^{\circ}$ & $\mathbf{4 5}^{\circ}$ \\
\hline 100 & 0.008 & 0.008 & 0.007 & 0.008 \\
\hline 120 & 0.009 & 0.009 & 0.007 & 0.009 \\
\hline 140 & 0.01 & 0.010 & 0.008 & 0.010 \\
\hline 160 & 0.011 & 0.010 & 0.008 & 0.010 \\
\hline 180 & 0.012 & 0.011 & 0.009 & 0.011 \\
\hline 200 & 0.013 & 0.010 & 0.010 & 0.012 \\
\hline 220 & 0.014 & 0.012 & 0.010 & 0.012 \\
\hline 240 & 0.015 & 0.012 & 0.011 & 0.013 \\
\hline & Table 6: Strain gauge readings. & \\
\hline
\end{tabular}




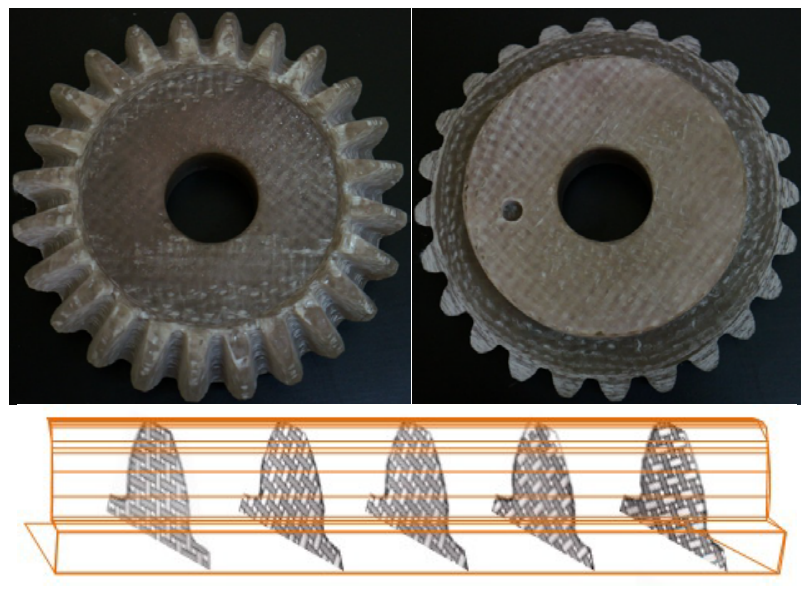

Figure 11: Glass fibre straight bevel gear model.

\begin{tabular}{|c|c|c|c|}
\hline $\begin{array}{c}\text { Mid Point } \\
\text { Tooth Surface }\end{array}$ & $\begin{array}{c}\text { FEA Results of } \\
\text { Glass/Epoxy }\end{array}$ & $\begin{array}{c}\text { Experimental } \\
\text { Results of Glass/ } \\
\text { Epoxy }\end{array}$ & $\begin{array}{c}\text { Percentage Error } \\
\text { EXP to FEA (Glass/ } \\
\text { Epoxy) }\end{array}$ \\
\cline { 1 - 1 } $\boldsymbol{\sigma}_{1}(\mathrm{Mpa})$ & \multirow{2}{*}{229.772} & 243.48 & 5.9659 \\
\cline { 1 - 1 } $\boldsymbol{\sigma}_{2}(\mathrm{Mpa})$ & & 293.15 & 27.583 \\
\cline { 1 - 1 } $\boldsymbol{\sigma}_{3}(\mathrm{Mpa})$ & \multicolumn{2}{|c|}{242.58} & 5.5742 \\
\hline \multicolumn{2}{|c|}{ The average of percentage error } & 13.041 \\
\hline
\end{tabular}

Table 7: Numerical and experimental results comparison.

accordance with the required performance. Based on the numerical results from the previous section, we found that the glass fibre has an intermediate level of stress compared to the steel bevel gear, while jute fibres showed high values of stress. The carbon fibre model showed very good results compared to the other composite materials, but if cost is taken into consideration, it will be too expensive.

As a result of this, we opted to use the woven roving glass fibre in the fabrication of the straight bevel gear, due its reasonably good results, excellent mechanical properties and low costs. In the fabrication process, we used the hand-layup technique, as previously mentioned and explained. Figure 11 shows the frontal view and the back view of the fabricated model, and how we arranged the fibre laminate in the gear's model. From the experimental phase, we came up with the strain reading on the midpoint section of the tooth surface, as shown in Table 6. In fact, only a few strain gauge readings were used, but it turned out to be very useful for FEA verification, and proved that composites can be used as a material for a straight bevel gear. The percentage of error between the numerical and experimental values is acceptable, and shown in Table 7.

\section{Conclusion}

The focus in this work is on how much the divergence in behaviour between orthotropic material and isotropic material such as steel can be reduced. Three types of orthotropic materials have been used as a straight bevel gear. Finite element method has been used in the numerical stage. After that we used a scientific method to select the best material to be used as a straight bevel gear. An effort has been made to determine the strain in the mid section of the gear tooth, which is considered a critical location in the gear model. Strain gauges have been used during the experimental stage, attached to the loaded surface profile of the gear tooth in order to measure the strain in three dimensions. These experimental readings have been compared with the numerical results. It is concluded that carbon/epoxy and glass-epoxy performs better compared to jute/epoxy, and is a viable alternative to steel gears. The reduced weight percentage for the straight bevel gear with glass-epoxy is $80 \%$ compared to the steel gear. We applied the COPRASS method to determine the optimum material gear, and it turned out to be glass/epoxy. The behaviour of orthotropic material gears and isentropic steel gears in terms of stiffness is similar. The stiffness of the carbon/epoxy gear is very close to the steel gear, in contrast, the jute/epoxy shows very low stiffness, leading us to conclude that natural fibres (jute) are unsuitable to be used as straight bevel gear material. In this study we used epoxy-hardener as the matrix while there are other types of matrix that can be used for future work depending on the application needed.

\section{Acknowledgement}

The researchers would like to thank the Ministry of Science, Technology and Innovation (MOSTI) Malaysia for their financial support of this work through the e-Science Fund Project No. 06-02-12-SF0072. In addition, the technical support of Curtin University Sarawak should be gratefully acknowledged.

\section{References}

1. Mao K (2007) A Numerical Method for Polymer Composite Gear Flash Temperature Prediction. Wear 262: 1321-1329.

2. Li W, Wood A, Weidig R, Mao K (2011) An Investigation on the Wear Behaviour of Dissimilar Polymer Gear Engagements. Wear 271: 2176-2183.

3. Mao K (2007) A New Approach for Polymer Composite Gear Design. Wear 262: 432-441.

4. Ganesan N, Vijayarangan S (1993) A Static Analysis of Metal Matrix Composite Spur Gear by Three-Dimensional Finite Element Method. Computers and Structures 46: 1021-1027.

5. Senthilvelan S, Gnanamoorthy R (2006) Effect of Gear Tooth Fillet Radius on the Performance of Injection Molded Nylon 6/6 gears. Materials and Design 27: 632-639.

6. Cedergren J, Srensen NJ, Melin S (2003) Numerical Investigation of Powder Compaction of Gear Wheels. International Journal of Solids and Structures 40: 4989-5000.

7. Ramesh TC, Ganesan N (1993) Studies on Metal Matrix Composite Railroad Wheels. Computers and Structures 47: 259-263.

8. Nozawa J, Komoto T, Kawai T, Kumehara H (2009) Tribological Properties of Polymer-Sheet-Adhered Metal Hybrid Gear. Wear 266: 893-897.

9. Kurokawa M, Uchiyama Y, Nagai S (1999) Performance of Plastic Gear Made of Carbon Fiber Reinforced Polyether- Ether-Ketone. Tribology International 32: 491-497.

10. Kurokawa M, Uchiyama Y, Nagai S (2000) Performance of Plastic Gear Made of Carbon Fiber Reinforced Poly-Ether-Ether-Ketone, Part 2. Tribology International 33: 715-721.

11. Kurokawa M, Uchiyama Y, Iwai T, Nagai S (2003) Performance of Plastic Gear Made of Carbon Fiber Reinforced Polyamide 12. Wear 254: 468-473.

12. Hoskins TJ, Dearn KD, Kukureka SN, Walton D (2011) Acoustic Noise from Polymer Gears A Tribological Investigation. Materials and Design 32: 35093515.

13. Senthilvelan S, Gnanamoorthy R (2007) Effect of Rotational Speed on The Performance of Unreinforced And Glass Fiber Reinforced Nylon 6 Spur Gears. Materials and Design 28: 765-772.

14. Simon V (2009) Head-Cutter for Optimal Tooth Modifications in Spiral Beve Gears. Mechanism and Machine Theory 44: 1420-1435.

15. Can Y, Misirli C (2008) Analysis of Spur Gear Forms With Tapered Tooth Profile. Materials and Design 29: 829-838.

16. Mendi F, Can H, Lekci MK (2006) Fatigue Properties of Polypropylene Involute Rack Gear Reinforced With Metallic Springs. Materials and Design 27: 427-433.

17. Aslantas K, Tas S (2004) A Study of Spur Gear Pitting Formation And Life Prediction. Wear 257: 1167-1175. 
Citation: Al-Qrimli HF, Almurib HA, Kumar N, Mahdi FA (2015) Dynamic Analysis of a Straight Bevel Gear Composite Structure. J Material Sci Eng 4: 152. doi:10.4172/2169-0022.1000152

Page 8 of 8

18. Duzcukoglu H (2009) PA 66 Spur Gear Durability Improvement with Tooth Width Modification. Materials and Design 30: 1060-1067.

19. Letzelter E, Vaujany JP, Chazeau L, Guingand M (2009) Quasi-Static Load Sharing Model In The Case Of Nylon 6/6 Cylindrical Gears. Materials and Design 30: 4360-4368

20. Hirogaki T, Aoyama E, Katayama T, Iwasaki S, Yagura Y, et al. (2004) Design systems for gear elements made of cotton fiber-reinforced plastics. Composite Structures 66 : 47-52.
21. Ansar M, Xinwei W, Chouwei Z (2011) Modeling strategies of $3 D$ woven composites: A review. Composite Structures 93: 1947-1963.

22. Chatterjee P, Athawale VM, Chakraborty S (2011) Materials Selection Using Complex Proportional Assessment and Evaluation of Mixed Data Methods. Material and Design 32: 851-860.

23. Chatterjee P, Chakrabort S (2012) Material Selection Using Preferential Ranking Methods. Material and Design 35: 384-393. 